\title{
EMÍLIO MOURA: CONTEMPLAÇÕES DO POETA-VIAJANTE
}

\section{EMÍLIO MOURA: CONTEMPLATIONS OF THE TRAVELER POET}

\author{
Viviana Pereira SILVA ${ }^{9}$ \\ Ilca Vieira de OLIVEIRA ${ }^{10}$
}

RESUMO: Ao longo dos séculos, muitos artistas usaram suas habilidades para representar a história de Minas Gerais, as belezas das cidades barrocas e o mistério de suas montanhas. Emílio Moura, a exemplo de outros poetas mineiros do século XX, usou sua arte para eternizar as cidades históricas; a diferença é que o poeta não utiliza pedra ou metal, que podem ser roídos pelo tempo e pelas intempéries; a matéria que Emílio Moura utiliza é a palavra poética. Nosso objetivo é analisar alguns poemas de Habitante da tarde (1969) e mostrar como o poeta empreende uma viagem metafórica pelas cidades mineiras, apreendendo o seu passado, transformando-o em poesia, na tentativa de proteger o patrimônio histórico da ação do tempo e da modernidade.

PALAVRAS-CHAVE: Poesia brasileira moderna; Emílio Moura; Cidades históricas de Minas Gerais; Viagem.

ABSTRACT: Over the centuries, many artists used their skills to represent the history of Minas Gerais, the beauty of the baroque cities and the mystery of its mountains. Emilio Moura, like other poets of the twentieth century, used his art to represent the historic cities, the difference is that the poet does not use stone or metal, which can be gnawed by time and weather; Emilio Moura uses the poetic word. Our goal is to analyze some poems of Habitante da tarde (1969) and show how the poet embarks on a metaphorical journey by Minas towns, representing their past, turning it into poetry, trying to protect the historical heritage of weather and modernity.

KEYWORDS: Brazilian modern poetry; Emilio Moura; Historical cities of Minas Gerais State; Travel.

Tudo em ti é viagem, será viagem. Viajas até mesmo ao redor de tua inacreditável imobilidade.

(MOURA, 2002, p.279).

\footnotetext{
${ }^{9}$ Mestranda. Programa de Pós-Graduação em Estudos Literários - Universidade Estadual de Montes Claros (UNIMONTES) - Montes Claros - MG - Brasil - CEP 39400-470 - vivas.girl@ hotmail.com / vivianapereirasilva@yahoo.com.br

${ }^{10}$ Orientadora. Departamento de Comunicação e Letras. Programa de Pós-Graduação em Estudos Literários (Mestrado) - Universidade Estadual de Montes Claros (UNIMONTES) - Montes Claros - MG - Brasil - CEP 39400-470 - ilca.vieira@pq.cnpq.br
} 
O poema a seguir encerra a primeira parte do livro Habitante da tarde (1969), de Emílio Moura; é um dos poucos versos que o poeta dedica a alguém. Apesar de ser tributado a Cyro dos Anjos, o poema esboça a própria poética emiliana. Vejamos, a seguir, os versos de Emílio Moura (2002, p. 234):

"Pastor de nuvens"

Navegaste em palavras e não viste teu dia abrir-se em flor, a flor em fruto.

Diante do mar apenas procuravas um marulho de concha a teus ouvidos.

Que estradas mais abstratas. Que cenários de papel inventaste! Nunca viste que outras paisagens, vivas, te sorriam. Só de esquivas imagens te cercavam.

Navegaste em palavras. Vivas? Mortas?

Belas, apenas? Dóceis, tinham asas, E era tudo uma vaga arquitetura:

tua amada, teu mundo, teu caminho, teu rebanho de nuvens, tantas nuvens, tua face no espelho, o próprio espelho.

Emílio Guimarães Moura nasceu em 1902, em Dores do Indaiá, e mudou-se para Belo Horizonte no início do século XX, onde conheceu Carlos Drummond de Andrade e outros companheiros com quem integrou o grupo modernista de Minas Gerais, dentre eles Abgar Renaut, Pedro Nava, Milton Campos, João Alphonsus e Aníbal Machado. Esse movimento de renovação literária consolidou-se em Minas Gerais a partir de 1924, quando o poeta francês Blaise Cendrars, acompanhado dos paulistas Mário de Andrade, Oswald de Andrade e Tarsila do Amaral vieram em uma "viagem de descoberta ao Brasil" conhecer as cidades históricas de Minas Gerais. Eles suscitaram nos mineiros o desejo de olhar para suas raízes barrocas e arcádicas, o que contribuiu significativamente para a formação de um movimento literário fortemente marcado pela aliança entre tradição e modernidade. Essa viagem estabeleceu um vínculo entre mineiros e paulistas, especialmente entre Mário e Drummond.

Emílio Moura destacou-se por sua filiação à tradição lírica de Minas Gerais, notadamente pela influência do simbolista Alphonsus de Guimaraens. Ele participou 
ativamente desse movimento em Minas, era poeta e crítico, publicou seus textos no Diário de Minas e ajudou a fundar A Revista, periódico que marcou a expansão das ideias modernistas para além das fronteiras de São Paulo e do Rio de Janeiro. Ele era um homem consciente das inovações literárias de sua época, mas não se rendeu aos exageros da linguagem, à ironia e ao poema-piada, como fez a maioria de seus companheiros de geração. Seus versos são simples, discretos, com um vocabulário fácil, onde ele aborda temas universais, como amor, morte, tristeza e solidão.

Desde o início sua poética foi colocada "sob o signo da pergunta". Os versos "Navegaste em palavras. Vivas? Mortas?/Belas, apenas?" são exemplo dos inúmeros questionamentos existentes em sua obra. Emílio acreditava que as interrogações criavam no leitor um "estado de poesia" e de perplexidade diante do mundo. Em uma das entrevistas que concedeu, Emílio Moura (1969, p. 4) declarou: "minha poesia não afirma. Afirmando, resolveria a priori tudo para o leitor. Interrogando eu ponho o mundo diante do leitor."

Nos versos "E era tudo uma vaga arquitetura: / tua amada, teu mundo, teu caminho, /teu rebanho de nuvens, tantas nuvens", o poeta descreve sua própria obra, marcada pela fluidez e abstração. Suas palavras brumosas não apreendem o mundo real, antes, criam um espaço onírico, onde a vida, a amada e o próprio mundo são idealizados. O título do poema "Pastor de nuvens" remete-nos a Drummond, que se declarou "fazendeiro do ar" ". Ilca Vieira de Oliveira (2011) afirma que "o poeta das interrogações se identifica com o gauchismo do amigo, pois se sente um ser torto e que também não encontra lugar no mundo". Assim, em desajuste com o mundo moderno, o poeta se torna um pastor de nuvens, que percorre as "estradas mais abstratas", que se cerca de "esquivas imagens", que recorre ao sonho e ao mito por meio da palavra poética como forma de manter-se vivo.

O verso final "tua face no espelho, o próprio espelho" parece ratificar a ideia de que o poeta está falando de si mesmo, uma vez que a metáfora do espelho é bem

\footnotetext{
${ }^{11}$ E, principalmente, a Cecília Meireles, que no poema "Destino" (Viagem, 1939), cunhou a expressão "Pastora de nuvens". Emblema simbólico do poeta, a metáfora contrapõe-no aos "Pastores da terra", conforme as duas primeiras estrofes do texto: "Pastora de nuvens, fui posta a serviço / por uma campina desamparada / que não principia nem também termina, / e onde nunca é noite e nunca madrugada. // (Pastores da terra, vós tendes sossego, / que olhais para o sol e encontrais direção. / Sabeis quando é tarde, sabeis quando é cedo. / Eu, não.) [...]" (MEIRELES, 1972, p.69). Desde então, a expressão metafórica ceciliana encontrou largo uso entre os poetas brasileiros, de Emílio Moura a Péricles Eugênio da Silva Ramos, entre outros. Na obra de Meireles, há pelo menos mais uma variante da imagem: a "Pastora descrida", título de um poema de Retrato natural (1949), que se abre com os tercetos: "Eu, pastora, que apascento / estrelas da madrugada / pelas campinas do vento, // fui falar ao eco antigo, / a cuja voz fui criada, / e que supus meu amigo. [...]" (MEIRELES, 1972, p.165-166) (Nota do Editor).
} 
recorrente em sua obra. $\mathrm{O}$ espelho na poética emiliana não é apenas um objeto capaz de duplicar ou simplesmente refletir a realidade e sim um instrumento que projeta um outro espaço, onde o eu é um outro; espaço "entre o real e a fábula", lugar do sonho e da fantasia, onde se pode dar asas à imaginação.

Ao longo de sua vida Emílio escreveu vários livros, dentre eles Ingenuidade, 1931; Canto da hora amarga, 1936; Cancioneiro, 1945; O espelho e a musa, 1949; e A casa, em 1961. Reuniu pessoalmente sua obra poética em 1969, no volume Itinerário poético, com dois livros inéditos: Habitante da tarde e Noite maior. Sua obra é harmoniosa, composta com altas doses de lirismo e introspecção; os temas são sempre os mesmos, por isso as variações no ritmo e na forma garantem que os versos não se tornem repetitivos.

Dos títulos mencionados, Habitante da tarde, 1969, apresenta alguns elementos interessantes. Este livro é dividido em três partes: "Tempo morto", "Lira mineira" e "Entre o real e a fábula". A primeira e a terceira parte apresentam o gosto por temas universais, a subjetividade e a variedade de recursos poéticos que conferem beleza e musicalidade aos versos, ratificando assim o acentuado lirismo do autor. A segunda parte merece destaque: os poemas de "Lira mineira" são dedicados a alguns amigos e a algumas cidades de Minas Gerais, aspecto incomum na obra de Emílio Moura. Até então, aparecera em sua poesia poucas referências explícitas à realidade, como o poema "Soneto a Carlos Drummond de Andrade", em O instante e o eterno, 1951-1953; e o longo poema "A casa", 1961; em que o poeta abre "os olhos à memória" e a casa onde viveu, em Dores do Indaiá, "salta do tempo" e faz viver "de novo, um menino". Em "Lira mineira" o poeta homenageia o amigo Drummond com o poema "Ao fazendeiro do ar”, e Aníbal Machado com “Advento de João Ternura”, além de fazer uma viagem pelo seu passado. Ele visita sua infância e algumas paisagens de Minas Gerais, especialmente as cidades históricas.

Emílio Moura teve uma "infância nômade, de cigano": nasceu em Dores do Indaiá, onde morou até os quatro anos; depois viveu em Bom Despacho, Carmo da Mata e Cláudio; por fim, em Belo Horizonte, onde morou até 1971, ano de sua morte. Foi o único dos intelectuais mineiros que não migrou para o Rio de Janeiro ou para São Paulo, passou toda a vida preso às montanhas de sua terra. Não gostava muito de sair de casa, mas fazia inúmeras viagens imaginárias pelo país dos sonhos. Em "Lira mineira" o sujeito lírico empreende uma viagem pelas cidades barrocas de Minas; viagem 
metafórica, uma vez que o poeta revisita esses espaços por meio da memória e da imaginação.

Em suas Crônicas de Viagem, Cecília Meireles fala da diferença que há entre um turista e um viajante. Eis o perfil do viajante por ela delineado:

O viajante é a criatura menos feliz, de movimentos mais vagarosos, todo enredado em afetos, querendo morar em cada coisa, descer à origem de tudo, amar loucamente cada aspecto do caminho, desde as pedras mais toscas às mais sublimadas almas do passado, do presente e até do futuro - um futuro que ele nem conhecerá. (MEIRELES, 1989, p. 101).

O sujeito poético de "Lira mineira" é essa criatura vagarosa e melancólica, que passeia por Minas Gerais. Ele não tem o olhar inquieto do turista, que deseja conhecer superficialmente os lugares e fotografar a paisagem; o poeta-viajante é meditativo, ele contempla as igrejas, os casarios coloniais e enxerga muito além de sua "pátina triste". "No alto das colunas, das fachadas, dos pórticos, das igrejas, deuses, reis, imperadores, santos, anjos lhe acenam, quando, por acaso, não estão entretidos uns com os outros, em fábulas, evangelhos, poesia, hinos celestiais", pois o viajante não é apenas um espectador, é um ser sensível que contempla o mundo ao seu redor e, aos poucos, vai se misturando à paisagem, tornando-se parte dessa história e desse lugar.

O poema "Casa de Marília", por exemplo, ilustra a contemplação do poeta, que afastado da História pela ação do tempo, já não enxerga o sofrimento e o impedimento amoroso. Ao dizer que "Pombos revoam/sobre o telhado" ele sugere leveza e liberdade, características que se opõem à atmosfera que cercava o inconfidente Tomás Antônio Gonzaga e sua amada Marília. O poeta evoca a musa árcade e assim resgata suas próprias raízes literárias, haja vista que Emílio também possui uma musa: Eliana. Além do gosto pelas formas líricas, que é uma herança dos árcades e dos simbolistas. A antítese nos versos "A morte e a vida,/ já de mãos dadas,/ não se repelem,/ antes procuram-se" remetem-nos, invariavelmente, ao barroco e suas tensões; esses versos sugerem ainda a relação existente entre passado e presente: o poeta habita o presente, mas por meio da imaginação ele consegue viver "no tempo,/ o que não houve."

O poema "Congonhas do Campo" evidencia o caráter viajante do poeta: "Tudo retorna à sua origem. Tudo é eterno." Ao contemplar profetas esculpidos por Aleijadinho, o sujeito lírico sente que "o adro rescende a eternidade", demonstrando que 
a arte é capaz de perenizar a História, torná-la eterna, pois o contato com esses monumentos conduz o ser humano a uma viagem imaginária ao passado.

Ao longo dos séculos, muitos artistas usaram suas habilidades para representar a história de Minas Gerais, as belezas das cidades barrocas e o mistério de suas montanhas. Vários poetas do século XX como Carlos Drummond de Andrade, Murilo Mendes, Cecília Meireles e o próprio Emílio Moura também usaram sua arte para eternizar as cidades históricas, a diferença é que eles não utilizaram a pedra ou o metal, que podem ser roídos pelo tempo ou pelas intempéries; a matéria desses artistas é a palavra poética. Esses poetas são capazes de apreender o passado histórico dessas cidades, transformando-o em poesia, na tentativa de proteger o patrimônio histórico da ação do tempo e da modernidade. Pode parecer contraditório que representantes do grupo modernista se vinculem à tradição, mas vale ressaltar que o Modernismo não é um movimento radical de ruptura com o passado. Os modernistas buscavam uma linguagem nova, queriam fazer uma literatura que fosse a expressão do Brasil, por isso era importante conhecer e valorizar a cultura brasileira. Carlos Drummond de Andrade (1980, p.63-71), no poema "A visita", de A paixão medida, retrata a visita que Mário de Andrade, um dos maiores líderes desse movimento, fez a Minas para conhecer o simbolista Alphonsus de Guimaraens, em 1924:

- Vim conhecer o Príncipe, vim saudar o Príncipe dos Poetas das Alterosas Montanhas!

$[\ldots]$

O alto visitante jovem inclina-se, compenetrado:

- O Príncipe não é príncipe, eu sei, para o distraído, fosfóreo descaso dos donos da literatura e da vida.

Mas é bem mais do que isso, para cada um de nós poucos obcecados pela vertigem do poema no cristal da linguagem. $[\ldots]$

O fragmento acima evidencia o respeito que Mário tinha por Alphonsus, que ainda não era um poeta muito conhecido, mas que já era admirado por alguns escritores “obcecados pela vertigem do poema no cristal da linguagem”. Essa visita, bem como a visita que a caravana paulista faz ao interior de Minas em 1924, é emblemática, pois demonstra o vínculo que os modernos estabeleceram com a tradição. $O$ intercâmbio com os paulistas foi importante para que os mineiros redescobrissem a literatura, a arte 
e a cultura de sua terra e que delineassem um perfil diferenciado do movimento modernista em Minas Gerais, que desde o início foi marcado pelo forte diálogo com a tradição árcade e barroca.

A poesia de Emílio Moura foi especialmente influenciada por essa tradição. O cunho universal de sua poética, a evocação à musa e o acentuado lirismo de seus versos sãos heranças árcades; assim como os conflitos, indagações e gosto pelas sombras, pela noite e pela neblina reportam-nos ao barroco e à paisagem histórica de Minas Gerais. $\mathrm{O}$ sujeito poético de "Lira mineira" viaja por Sabará, Congonhas do Campo e Ouro Preto, que aparece em evidência, dada sua importância histórica, política e econômica. Além do poema "Casa de Marília", que faz uma referência indireta à cidade, há ainda cinco poemas dedicados à antiga Vila Rica: "Ouro Preto I", "Ouro Preto II", "Noturno de Ouro Preto I", "Noturno de Ouro Preto II" e "Meditação, à tarde, em Ouro Preto".

Segundo Michel Onfray o viajante precisa criar algumas referências para organizar o conjunto da viagem e mais tarde formar uma "geografia sentimental". Para tanto, o viajante pode utilizar várias técnicas, como a fotografia, a pintura, uma anotação ou um cartão postal, mas salienta:

[...] somente a experiência escrita permite dar conta da totalidade dos sentidos. Os outros suportes são relativamente pobres: a aquarela, o desenho, a foto captam o real numa de suas modalidades - a cor, a linha, o traço, o desenho, a imagem -, nunca da forma integral. Já o poema, como quintessência do texto, mas também da prosa, podem captar e restituir um cheiro de jasmim do Oriente, uma luz acima de uma cidade que reflete nas águas de um rio, uma temperatura morna numa floresta tropical saturada dos perfumes de terra, húmus e folhas em decomposição, o murmúrio de um riacho dissimulado no ar úmido ou a umidade desse lugar. (ONFRAY, 2009, p. 100).

O poeta-viajante de "Lira mineira" passeia por Ouro Preto e traduz em poesia as impressões que a cidade lhe provoca, como podemos comprovar no trecho de "Ouro Preto I": "Que frio!/A neblina rói a paisagem/Sinto o tempo parado em cada pedra que piso." O poeta nos transporta ao clima úmido e brumoso da cidade e nos faz refletir sobre a fragilidade dos monumentos que estão expostos à chuva, ao sol, ao vento; reportando-nos, assim, à efemeridade da vida. O sujeito lírico sente "o tempo parado", sentimento inerente a todo viajante, que, ao contrário do turista, não passeia à toa pelas ruas de uma cidade histórica, mas apreende o sentido de cada lugar, de cada detalhe. O poeta é capaz de voltar no tempo e (re) viver os acontecimentos que ocorreram naquele lugar. 
O poema "Ouro Preto II" apresenta-nos uma cidade sombria, em uma noite fria e nebulosa, cheia de anjos e espectros que murmuram coisas "ligadas à aflição mais dura:/ morte, exílio, remorso, desvario". O sujeito-lírico ouve o "suspiro eterno" dos "mártires e amantes" e se inquieta com o possível sofrimento vivido pelos inconfidentes e suas amadas. No soneto "Noturno de Ouro Preto I" o sujeito poético declara à cidade:

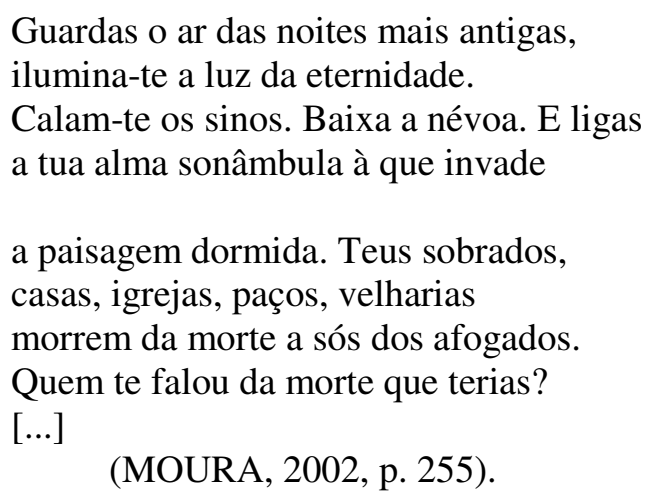

Mais uma vez o poeta concebe a cidade como guardiã da História, como espaço privilegiado, iluminado pela "luz da eternidade". Entretanto, ele evidencia uma preocupação com os "sobrados, casas, igrejas, paços, velharias", que, apesar dos cuidados do IPHAN - Instituto do Patrimônio Histórico e Artístico Nacional - são constantemente ameaçados pelo tempo e pelas intempéries.

"Noturno de Ouro Preto II" é dedicado a Murilo Mendes, poeta mineiro que escreveu Contemplação de Ouro Preto entre 1949 e 1950. O poema Emiliano é marcado por várias indagações de um inquieto eu-lírico que quer desvendar os segredos das vozes sofridas e dos espectros que chamam sem cessar no meio da noite "submersa em labirintos de sono". Algumas expressões como "espectro a vagar", "avesso do sonho", "fluir do tempo" e "invisível cortejo" demonstram a atmosfera abstrata e fantasmagórica recriada por Emílio Moura, reportando-nos, assim, à poética de Murilo Mendes, que também possui alguns elementos vagos e fugidios.

O poema "Meditação, à tarde, em Ouro Preto" ilustra bem o papel do viajante; ao meditar, o sujeito lírico transcende, liberta-se; por isso é capaz de voltar ao passado e ouvir melodias que sobem dos ermos, ouvir "vívidos ecos" que "soam como vozes ainda vivas". As interrogações também sugerem que o poeta é meditativo: "Que segredos/ saltam destas ladeiras? Que horas caem/ de pêndulos perdidos?/ Quem caminha sobre este chão/ Quem parte e não regressa?" O poeta se inquieta com o desejo de conhecer a história e os segredos desses lugares. “Ah, Nizes e Marílias!", nesse verso 
o sujeito poético se refere às musas árcades; seus nomes aparecem no plural para representar as tantas mulheres que viveram naqueles sobrados e que também não puderam realizar seus amores. Os versos "Sombras de olvido, pátinas de cinza/ tudo apagam" denotam que não só o tempo apaga a paisagem; o esquecimento também corrói a História, por isso o poeta assume uma postura diante dessa situação: "Sou apenas memória".

Emílio Moura reveste-se da memória para imortalizar a história de Minas e das cidades barrocas. Segundo Michel Onfray, para organizar a memória, o viajante deve colher as emoções e sensações que um lugar lhe despertou e ordená-las de maneira que tenham um sentido e por último, utilizar alguma técnica que ajude a "fixar o instante" para que a viagem se torne imortal. Emílio Moura escolheu a poesia, que para Onfray é a técnica que "permite, por certo, a aproximação mais sutil, mas a mais volátil igualmente. Quanto mais abundantes a imagem e as sinestesias, mais o epicentro do real aparece, mas este se mostra também mais frágil, delicado, evanescente."

A poesia de Moura é essencialmente evanescente, de caráter abstrato, mesmo quando os temas são ligados à realidade, como em "Lira mineira". Nesse caso, transformar a realidade em poesia é uma maneira de eternizar o passado histórico de Minas Gerais, uma vez que "as horas passam, os homens caem,/ a poesia fica". Emílio Moura está inserido em um lugar no tempo e na história; sua poesia, entretanto, transcende esse espaço. Apesar de integrar um movimento de renovação literária, Moura não se rendeu aos modismos de sua época, nem se filiou a nenhuma escola; sua poesia não possui prazo de validade, por isso muitos críticos de sua época tiveram dificuldades em examinar sua obra. Talvez ninguém tenha se aproximado de uma definição plausível tanto quanto o crítico e amigo Carlos Drummond de Andrade, que declarou: “poesia, teu doce apelido é Emílio”.

\section{REFERÊNCIAS}

ANDRADE, C. D. de. A paixão medida. In: Poesia Completa. Rio de Janeiro: Nova Aguilar, 2002.

A paixão medida. 2.ed. Rio de Janeiro: J. Olympio, 1980.

ARAÚJO, L. C. de. A poesia modernista de Minas. In: ÁVILA, A. O modernismo. São Paulo: Perspectiva, 1975. p.179-191.

BOSI, A. O ser e o tempo da poesia. São Paulo: Companhia das Letras, 2000. p.163227. 
MEIRELES, C. Roma, turistas e viajantes. In: Crônicas de viagem 2. Rio de Janeiro: Nova Fronteira, 1989. p. 101-104.

Flor de poemas. 4.ed. Rio de Janeiro: Nova Fronteira, 1972.

MOURA, E. Itinerário poético: poemas reunidos. 2.ed. Belo Horizonte: UFMG, 2002.

Habitante da tarde. In: Itinerário poético: poemas reunidos. 2.ed. Belo

Horizonte: UFMG, 2002.

OLIVEIRA, I. V. de. Ouro Preto e a meditação dos poetas Carlos Drummond de Andrade e Emílio Moura. Anais do I Encontro Nacional do GT Teoria do Texto Poético (ANPOLL) - O legado moderno e a (dis)solução contemporânea [2009], Araraquara/Goiânia, dezembro de 2009. Disponível em: http://www.textopoetico.com.br/index.php?option=com_content\&view=article\&id=21 \&Itemid=14 Acesso em 02 de fevereiro de 2011.

ONFRAY, M. Teoria da viagem: poética da geografia. Porto Alegre: L\&PM, 2009.

Artigo recebido em 30/04/2011

Aceito para publicação em 02/08/2011 